\title{
DESENVOLVIMENTO DE UMA ESTRATÉGIA DE MANUFATURA EM UM AMBIENTE TURBULENTO
}

Henrique Luiz Corrêa

Engenheiro de Produção e Mestre em Engenharia pela Escola Politécnica da USP e PhD em Operations Management pela Warwick Business School, Inglaterra. É professor em vários cursos de MBA em São Paulo e Consultor da Gianesi Corrêa \& Associados. E-mail: gianesi.correa@originet.com.br

Paulo José Lentino de Camargo Prochno Engenheiro de Produção pela Escola Politécnica da USP, MBA pela Universidade de Vanderbilt, EUA, e Doutorando do INSEAD,

Fontainebleau, França

RESUMO: O artigo descreve um processo de desenvolvimento de estratégia de manufatura em uma fábrica brasileira de embalagens metálicas. São desenvolvidas ferramentas específicas para lidar com a alta turbulência característica do ambiente industrial brasileiro. Entre elas, destacam-se os chamados "modelos contingenciais", a "matriz de correspondências" e a "matriz importância-desempenho" para negociações entre clientes e fornecedores internos.

ABSTRACT: The article describes a manufacturing strategy development process in a Brazilian tin-plated can manufacturer. Some tools and frameworks specifically designed to deal with the turbulence of the Brazilian industrial environment are presented. Amongst them, the "contingency models", the "correspondence matrix", and the "importance-performance matrix" (adapted to support the negotiation process between internal customers and suppliers).

PALAVRAS-CHAVE: estratégia de manufatura, ambiente industrial brasileiro, processos de negociações.

KEY WORDS: manufacturing strategy, Brazilian industrial environment, negotiation processes. 
O pequeno número de "estudos de caso" apresentados na literatura sobre processos de desenvolvimento de estratégias de manufatura não condiz com a importância do tema. Além do mais, os autores neste campo geralmente descrevem o que fazer, mas nem sempre examinam em maior detalhe o como fazer. Há, contudo, alguns autores cujos trabalhos podem ajudar na difícil tarefa de desenvolver uma estratégia de manufatura em situações reais. Dois exemplos são as folhas de trabalho desenvolvidas por Platts e Gregory, ${ }^{1}$ que são ferramentas interessantes para ajudar a definir as prioridades de manufatura e a matriz importância-desempenho proposta por Slack, ${ }^{2}$ ambas relativamente fáceis de usar e efetivas em dar aos gerentes uma clara idéia de quais critérios de desempenho necessitam de uma ação urgente de melhoria no âmbito da manufatura. Contudo, alguns aspectos importantes do desenvolvimento de processos de estratégia de manufatura ainda carecem de métodos adequados de operacionalização. A função proativa da manufatura é um exemplo. Proatividade, particularmente em ambientes turbulentos, não é simplesmente algo que pode dar às empresas uma vantagem competitiva. É, às vezes, condição de sobrevivência. De fato, proatividade em manufatura é recomendada por numerosos autores (sendo Hayes e Wheelwright ${ }^{3}$ o exemplo mais eloquiente), porém poucos realmente indicam como ela deve ser realizada e como chegar a atingi-la.

Quebrar barreiras funcionais é o segundo exemplo. Em ambientes turbulentos, nos quais a mudança não é uma exceção e sim uma lei, a comunicação interfuncional torna-se essencial para permitir respostas rápidas às frequientes e repentinas mudanças. Os autores da literatura geralmente concordam que, para uma estratégia de manufatura realmente ser posta em prática, é necessário que as barreiras funcionais sejam quebradas. Muito da discussão de reengenharia gravita em torno desse aspecto. Contudo, poucos autores no campo da estratégia de manufatura lidam especificamente com métodos que operacionalizem modos de superar ou, ao menos, reduzir os aspectos negativos das barreiras interfuncionais.

O caso e as proposições descritos aqui objetivam contribuir para a pesquisa sobre processos de estratégia de manufatura, relatando uma experiência de desenvolvimento estratégico em manufatura em um ambiente turbulento, especificamente destacando aspectos como a proatividade em manufatura e a integração interfuncional, e esboçando algumas conclusões que poderão ajudar outras empresas que operem em condições semelhantes.

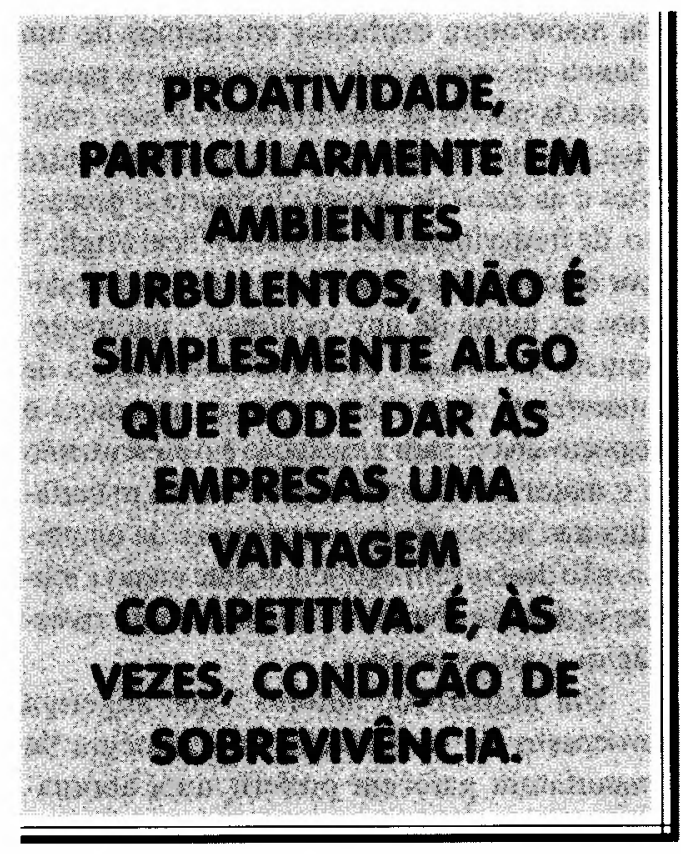

\section{BREVE REVISÃo BIBLIOGRÁFICA}

Numerosos autores na literatura $\mathrm{a}^{4}$ concordam que um importante objetivo de estratégia em manufatura é apoiar a estratégia da organização em sua perseguição por vantagens competitivas.

De acordo com muitos deles, o desenvolvimento de estratégias de manufatura deve seguir uma abordagem top-down (de cima para baixo). Skinner, ${ }^{5}$ Fine e Hax, ${ }^{6}$ Platts e Gregory, ${ }^{7}$ Slack $^{8}$ e, até certo ponto, Hill $^{9}$ sugerem modelos hierárquicos nos quais a estratégia corporativa conduz a estratégia de negócios. Esta, por sua vez, conduz a estratégia de manufatura e de outras áreas funcionais dentro de uma unidade de negócios. O processo de formulação de estratégias de manufatura na literatura não tem recebido tanta atenção quanto o chamado conteúdo da estratégia de manufatu-
* Este artigo, publicado originalmente no International Journal of Operations and Production Management (periódico oficial da European Operations Management Association), em novembro de 1995, foi recentemente premiado - "Literati Club Outstanding Paper Award" - , tendo sido considerado o melhor artigo de 1995 pelo Editorial Board do período.

1. PLATTS, K. W., GREGORY, M. J. Competitive manufacturing: a practical approach to the development of a manufacturing strategy. London: IFS, 1988.

2. SLACK, N. The manufacturing advantage. London: Mercury Books, 1991

3. HAYES, R., WHEELWRIGHT, S. C. Restoring our competitive edge. New York: The Free Press, 1984.

4. PLATTS, K. W. GREGORY, M. J. Op. cit.; SLACK, N. Op. cit.; HAYES, R., WHEELWRIGHT, S. C. Op. cit.

5. SKINNER, W. Manufacturing: the formidable competitive weapon. New York: John Wiley and Sons, 1985.

6. FINE, C. H., HAX, A. C. Manufacturing in a new perspective. Working paper n.86/ 42. Insead: Fontainebleau, 1985.

7. PLATTS, K. W., GREGORY, M. J. Op. cit. 8. SLACK, N. Op. cit.

9. HILL, T. Manufacturing strategy: the strategic management of the manufacturing function. 2.ed. London: MacMillan Press, 1993. 
10. LEONG, G. K. et al. Research in the process and content of manufacturing strategy. OGEMa International Joumal of Management Sciences. v.18, n.2., p.10922, 1990 .

11. HILL, T. Op. cit.

12. LEONG, G. K. et al. Op. cit.

13. HAYES, R., WHEELWRIGHT, S. C. Op. cit.

14. PLATTS, K. W., GREGORY, M. J., op. cit.; JOUFFROY, F., TARONDEAU, J. A. methodological framework for the formulation of an industrial strategy. Proceedings of the 5th International Conference of the Operations Management Association UK Manufacturing Strategy - Theory and Practice. UK: University of Warwick, June 1990. ra - os seus objetivos e áreas de decisão $0^{10}$; dentre os pioneiros neste campo, Hill" parece ser um dos poucos que realmente fizeram um exame mais detalhado da questão, propondo uma estrutura para guiar o desenvolvimento do processo passo a passo.

Essa abordagem, de acordo com Leong et al., ${ }^{12}$ parece considerar alguns processos implícitos, os quais dependem da classificação das decisões de manufatura nas chamadas áreas de decisão e de tornar os objetivos da manufatura explícitos em termos de um elenco de critérios de desempenho a perseguir. Os passos de identificação desses critérios, sua priorização e o relacionamento entre eles e as áreas de decisão formaria o processo, de forma implícita. Hayes e Wheelwright, ${ }^{13}$ por exemplo, embora descrevam quatro estágios ao longo de um "contínuo", que representam a evolução do papel da estratégia de manufatura dentro das empresas, nas quais o aspecto-chave para a evolução é o crescimento e o maior envolvimento proativo da manufatura nas necessidades estratégicas da empresa, não descrevem explicitamente como a empresa deveria comportar-se para atingir os estágios mais avançados.

Um número de autores ${ }^{14}$ que sugerem processos de formulação de estratégia da manufatura parecem preferir uma abordagem que poderia ser chamada de abordagem de auditoria. Eles não abandonam a abordagem top-down, mas a unem com a idéia de auditoria. $O$ processo de auditoria objetiva guiar o usuário através de um processo lógico de identificação dos objetivos, medição do desempenho atual, determinação do efeito das práticas atuais e identificação de onde mudanças são necessárias. Isso auxilia o usuário a priorizar ações, mas não modifica a abordagem básica top-down.

\section{OS MODELOS ENCONTRADOS NA LITERATURA E SUA INADEQUAÇÃO AO AMBIENTE TURBULENTO BRASILEIRO}

\section{Mudança é um conceito central no gerenciamento de organizações no Brasil}

Trabalhos de pesquisa desenvolvidos pela Universidade de São Paulo identificaram uma tendência entre empresas multinacionais de enviar executivos para suas filiais brasileiras com o objetivo de serem treinados em gerenciar em condições muito desfavoráveis. O Brasil tem sido, portanto, considerado um "laboratório" de treinamento para condições incertas e desfavoráveis. Realmente, nos últimos anos, o turbulento contexto industrial/econômico faz do planejamento a longo prazo uma tarefa difícil para a maioria das empresas que operam no Brasil. Os altos e instáveis níveis de inflação até anos recentes, as constantes mudanças governamentais na política industrial (tomemos como exemplo a taxa de importação para carros: $250 \%$ em janeiro de 1993, $20 \%$ em janeiro de 1994 , $32 \%$ em janeiro de $1995,70 \%$ em abril de 1995 , todas mudadas pelo governo com curto aviso prévio), altas taxas de juros e a turbulência política na qual o Brasil tem se encontrado nos últimos anos têm forçado as empresas a adotar predominantemente abordagens reativas - sempre "apagando incêndios" - para gerenciamento ("seis meses é um planejamento a longo prazo no Brasil", nas palavras de um gerente brasileiro). Tais abordagens normalmente consomem substanciais doses de esforço gerencial e recursos que, em consequiência, não são utilizados para a gestão estratégica.

Respostas efetivas a mudanças, portanto, parecem ser uma parte dominante das atividades gerenciais no Brasil. Qualquer estrutura que objetive ser eficiente em apoiar o desenvolvimento de estratégias de manufatura no Brasil deve ter a preocupação em considerar as mudanças e dar eficientes respostas a elas, como conceito central. Ao analisar essa realidade e, ao mesmo tempo, tendo em mente os modelos encontrados na literatura, alguns aspectos começam a consolidar-se como necessários para a construção de uma estrutura que vise auxiliar no desenvolvimento de estratégias de manufatura no Brasil:

- O tamanho das mudanças: as mudanças externas que afetam as organizações são tão freqüentes e relevantes que deveriam ser o principal gatilho para o processo de replanejamento e não apenas o tempo, como a literatura muitas vezes sugere. A empresa não pode suportar a espera de, digamos, seis meses para alterar sua direção estratégica, 
uma vez que uma mudança relevante (tal como uma drástica variação na taxa de importação nos produtos que ela fabrica _- favorecendo concorrentes — ou nas mercadorias que ela compra - nesse caso, favorecendo a própria empresa ) tenha acontecido.

- A variedade e a freqüência das mudanças: mudanças podem freqüentemente afetar tantas áreas funcionais que é impossível para apenas uma ou poucas dessas áreas manterem essas mudanças monitoradas e sob controle. Cada função deveria, portanto, adotar uma atitude proativa, tentando antecipar as mudanças e pensar eventualmente sobre a possibilidade futura de mudanças que se relacionem ao seu principal campo de interesse. $\mathrm{Na}$ literatura, embora a maioria dos autores advogue a necessidade de uma manufatura proativa, a maior parte das estruturas sugeridas são, na realidade, top-down. Nenhuma maneira formal de auxiliar a função de manufatura a exercer sua contribuição de forma proativa parece ser oferecida pela maioria dos autores. Eles parecem confiar unicamente nas atitudes das pessoas para fazer a manufatura proativa funcionar. Parece ser arriscado, contudo, assumir que os gerentes irão adotar uma atitude proativa a curto prazo, principalmente em ambientes turbulentos como o mercado brasileiro, no qual os gerentes de manufatura têm tido um papel historicamente reativo.

- A importância de quebrar barreiras organizacionais: quebrar barreiras organizacionais é absolutamente essencial para a empresa se adaptar e responder efetivamente e como um todo coerente em face de tais mudanças ambientais. Embora os autores de modo geral concordem que quebrar as barreiras interfuncionais dentro da organização é necessário, quando se analisam alguns métodos encontrados na literatura, tal como o de Hill, ${ }^{15}$ por exemplo, tem-se a impressão de que há somente duas funções dentro da organização: marketing e manufatura. A adoção estrita de tal método pode representar um risco de repetir um dos erros básicos que dispararam todo o "movimento" da estratégia de manufatura: o confinamento do processo de ges- tão estratégica dentro dos limites de uma ou poucas áreas funcionais dentro da organização. O processo de formulação estratégica deveria, assim, considerar explicitamente todas as funções relevantes dentro da organização.

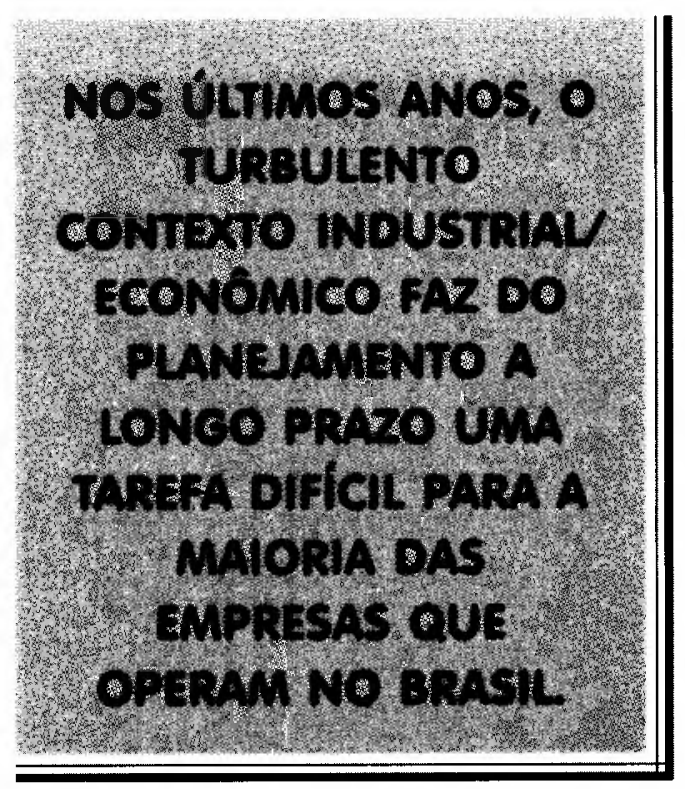

Com esses aspectos em mente, os autores introduziram um exercício para encontrar maneiras de operacionalizá-los em termos de uma estrutura consistente, que poderia ser mais apropriada para o ambiente brasileiro. Decidiu-se adotar uma pesquisa ativa (action research) para desenvolver um modelo e, então, uma empresa foi escolhida para abrigar o exercício.

\section{A EMPRESA EM ESTUDO}

O trabalho relatado aqui foi desenvolvido numa empresa de manufatura de embalagens metálicas, localizada em São Paulo. Será chamada, neste artigo, "Empresa X". Tem aproximadamente 1.000 empregados e quatro fábricas. Em 1994 o faturamento da Empresa $\mathrm{X}$ foi de aproximadamente US\$ 60 milhões, ocupando então a quarta colocação na indústria brasileira de latas. O trabalho apresentado aqui foi desenvolvido na maior fábrica da Empresa X em São Paulo, responsável por mais de $60 \%$ de suas vendas. Esta fábrica tem 700 trabalhadores e produz dez diferentes tipos de latas. A maioria dos clientes da Em- 
presa $\mathrm{X}$ são grandes empresas químicas e alimentícias. As latas são normalmente feitas atendendo a pedidos. A empresa tem um programa de "qualidade total" em curso e pretendia, quando da elaboração da pesquisa, obter o certificado ISO 9002 até o final de 1995.

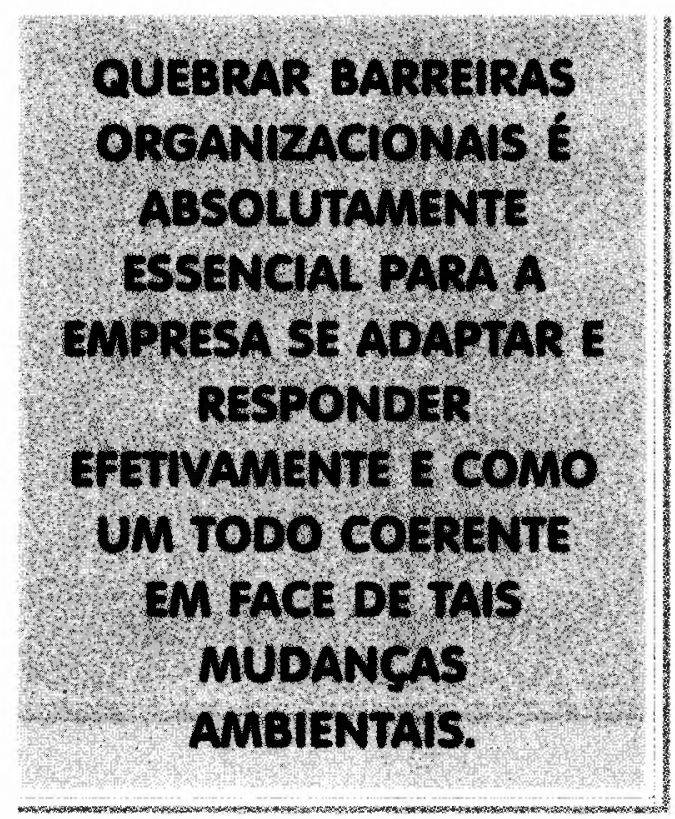

\section{O processo}

A idéia de desenvolver uma estratégia de manufatura para a Empresa X foi inicialmente proposta em 1993. Enquanto desenvolvia suas atividades operacionais como engenheiro de produção trabalhando para a empresa, um dos autores percebeu as sérias dificuldades que os gerentes da Empresa $\mathrm{X}$ enfrentavam em seus processos decisórios devido à falta de direção estratégica bem definida. Após apresentar uma série de seminários sobre o tema à gerência intermediária, apresentando alguns conceitos básicos de estratégia de manufatura encontrados na literatura, ${ }^{16}$ alguns dos médios gerentes começaram a se envolver com a idéia. Breve os conceitos de estratégia de manufatura tornaram-se questões correntes naquele nível gerencial. $O$ desenvolvimento efetivo e a implementação do processo em si, contudo, ainda necessitava da aprovação da alta direção para serem postos em prática.
Apesar dos esforços, inicialmente a alta direção não ficou convencida dos benefícios tangíveis do projeto. Cansados como estavam das muitas e frequientes mudanças radicais de direção do governo no Brasil, não é surpreendente que a alta direção preferisse adotar uma postura mais conservadora. A proposta tinha quase sido considerada como mais um dos dispendiosos modismos da manufatura: “... dois anos atrás, qualidade total, um ano atrás, ISO, este ano, estratégia de manufatura; o que vem depois?...". Além disso, a empresa vinha tendo resultados razoavelmente bons nos últimos três anos - na visão da alta direção, não era hora de mudar. Alguns dos gerentes médios não concordaram totalmente com a posição da alta direção, já que eles vinham sofrendo com o problema de não ter uma clara direção estratégica na qual basear suas decisões operacionais. A gerência média, então, propôs o desenvolvimento de um "projeto-piloto" de estratégia de manufatura em uma das áreas da empresa, que iria exigir pouco comprometimento da alta direção.

O projeto-piloto seria acionado pela própria média gerência, que seria responsável pela formulação das estratégias de manufatura e pela sua operacionalização na área-piloto. Baseados nos resultados (possivelmente mais tangíveis) do piloto, a alta direção iria então decidir se o projeto deveria ser estendido para toda a empresa. Esse arranjo foi aceito pela alta direção e o processo se iniciou. Nesse caminho, ao contrário da tradicional abordagem top-down, o processo inicia-se seguindo o que pode ser chamado uma abordagem "middle-down-top-down": disparado no nível da média gerência, descendo para a operacionalização na área-piloto e subindo à alta direção. Baseada então nos resultados do projeto-piloto, seria mais possível à alta direção avaliar e decidir se o projeto deveria ser estendido para toda a empresa. A Figura 1 mostra o modelo de implementação proposto.

Como o processo é disparado pela média gerência, esta está profundamente envolvida com o projeto desde o início, tornando o processo de implementação mais fácil e rápido.
16. SLACK, N. Op. cit.; HAYES, R.,
WHEELWRIGHT, S. C. Op. cit:; FINE, C.H., HAX, A. C. Op. cit. 
Figura 1 - 0 modelo de implantaçāo proposto

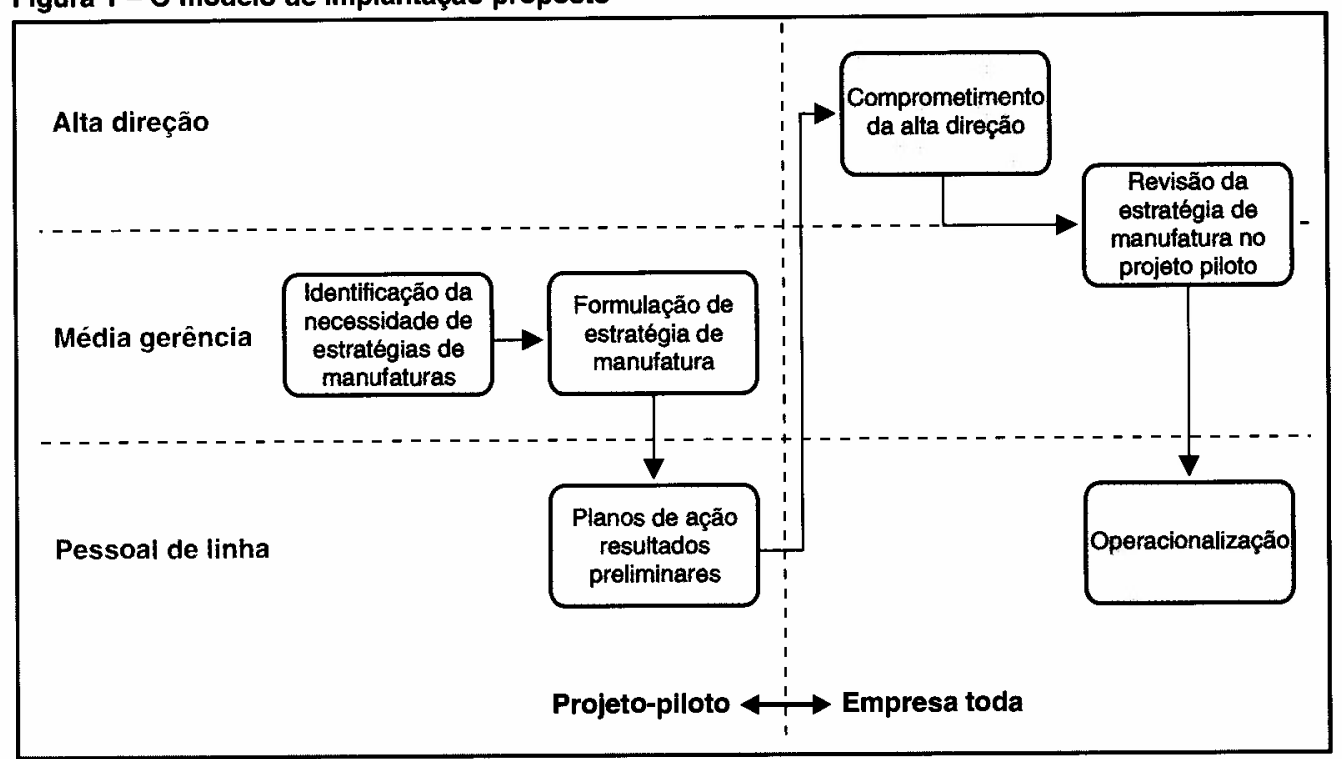

\section{Primeiros passos no processo}

Como o processo não seria conduzido pela própria alta direção, parecia necessário formar um grupo de pessoas interessadas em seu desenvolvimento para, então, dirigi-lo. Este grupo foi formado pelo engenheiro que havia inicialmente proposto a idéia (seria o facilitador do processo) e cinco gerentes de nível médio (manufatura, finanças, vendas, compras e recursos humanos). Esse grupo será, neste artigo, denominado de GEM (Grupo Estratégico de Manufatura).

Como estratégia de manufatura era um tema novo na empresa, o processo iniciouse com a aplicação de um questionário para os principais gerentes envolvidos com o projeto-piloto. $\mathrm{O}$ objetivo era avaliar suas percepções em relação ao papel da manufatura no planejamento da empresa e suas visões acerca dos relacionamentos entre questões estratégicas e operacionais na manufatura. Hum e Leow, ${ }^{17}$ estudando o nível de consciência dos gerentes operacionais em relação às questões estratégicas operacionais, desenvolveram com sucesso uma pesquisa com 200 empresas pertencentes à indústria eletrônica em Singapura. Baseados no instrumento de pesquisa de Hum and Leow, o questionário foi composto de 18 afirmações a serem analisadas pelos respondentes e marcadas por eles usando uma escala Likert de cinco pontos ordena- dos de "concordo totalmente" a "discordo totalmente". O objetivo do questionário era duplo: começar a ter um melhor entendimento do grau de acordo entre os gerentes sobre as questões de estratégia de manufamanufatura na visão deles para a competitividade da empresa; resumindo, trazer a questão da estratégia de manufatura para as agendas pessoais dos indivíduos.

Da análise das respostas do questionário, ficou claro que, embora a importância estratégica da manufatura fosse geralmente reconhecida, o papel da manufatura era visto com predominantemente "reativo". A maior parte dos gerentes (78\% das respostas) consideravam que a manufatura realizava bem seu trabalho quando era capaz de responder bem a qualquer exigência do departamento de vendas. Os trade-offs entre diferentes critérios competitivos tais como qualidade, custo, flexibilidade, velocidade e confiabilidade ${ }^{18}$ também não eram reconhecidos explicitamente pelos gerentes. A mentalidade de "qualidade total" dominava: "nós devemos ser capazes de ser excelentes em tudo", por exemplo, foi a afirmativa confirmada por cerca de 90\% dos respondentes.

Após essa primeira coleta de dados, uma série de seminários foi preparada e administrada para discutir os porquês por trás das discrepâncias entre as diferentes visões dos gerentes refletidas pelos questionários. Um tura e a importância, papel e influência da
17. HUM, S., LEOW, L. The perception of the strategic role of manufacturing amongst operations managers: an empirical study based on a newly industrialized economy. International Journal of Operations and Production Management. v.12, n.11, p.15-23, 1992.

18. SLACK, N. Op. cit. 
segundo objetivo dos questionários foi tentar chegar a um consenso em relação aos conceitos de estratégia de manufatura. Após os seminários, foi então hora de procurar o acordo dos gerentes envolvidos em relação às prioridades competitivas de manufatura ou, em outras palavras, a definição de quais critérios de desempenho da manufatura poderiam mais contribuir para a força competitiva da empresa.

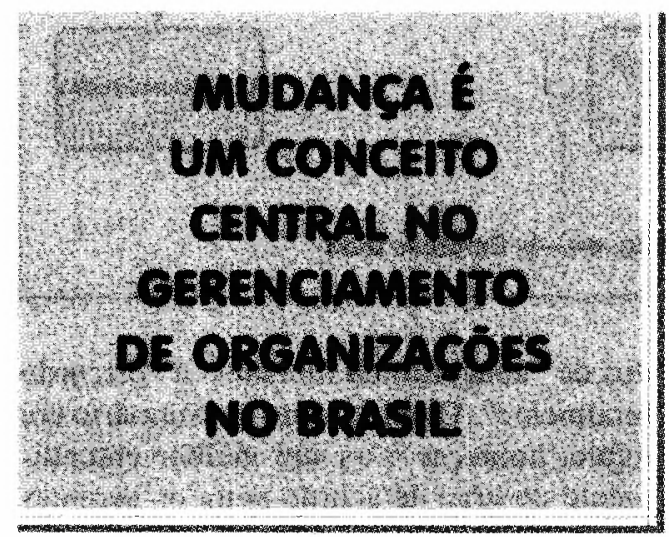

\section{Determinando as prioridades em manufatura: reunindo dados}

Para determinar os critérios competitivos mais relevantes da manufatura, as seguintes atividades foram desempenhadas:

- entrevistas diretas com consumidores. O gerente de vendas selecionou cinco clientes que foram considerados representativos dos 80 clientes da empresa. Estes cinco clientes foram entrevistados por um time de membros da manufatura da Empresa X e do departamento de vendas, objetivando identificar a importância dada pelo cliente aos vários critérios competitivos (custo, qualidade, velocidade, confiabilidade e flexibilidade) e a visão dos clientes sobre o desempenho da Empresa X nos mesmos critérios quando comparada com seus principais concorrentes.

- contribuição das visões dos gerentes da Empresa X. Folhas de trabalho adaptadas 19. PLATTS, K. W., GREGORY, M. J. Op. cit.

20. SLACK, N. Op. cit. manufatura mais importantes, de acordo com os gerentes da Empresa X. O objetivo era avaliar a percepção dos gerentes em relação à importância de cada critério e também sua percepção do desempenho da empresa nesses critérios quando comparada com os concorrentes. Três folhas de trabalho foram utilizadas: a primeira, objetivando determinar o critério de importância, pediu aos gerentes para distribuir 100 pontos entre os critérios que eles considerassem ser "ganhadores de pedidos" do cliente, de acordo e proporcionalmente à importância de cada um dos critérios. Os critérios considerados como qualificadores foram marcados com "Q". A segunda folha de trabalho objetivava julgar o desempenho da empresa quando comparada aos concorrentes: pediu-se aos gerentes para classificar cada critério na escala ordenada de -3 (desempenho muito inferior ao dos concorrentes) a +3 (desempenho muito superior ao dos concorrentes). A última folha de trabalho pediu aos gerentes para identificar oportunidades e ameaças externas, visando reunir informações sobre opções futuras da empresa. Enquanto preenchiam as folhas de trabalho, os gerentes podiam dividir as respostas se sentissem que os produtos competiam em diferentes segmentos de mercado.

Um resumo dos resultados das folhas de trabalho e das informações mais relevantes das entrevistas com os clientes foi distribuída para os membros do GEM. Uma reunião foi feita para discutir os resultados e estabelecer uma ordem das prioridades determinadas para a empresa. A ferramenta utilizada nesta fase foi a matriz proposta por Slack. ${ }^{20} \mathrm{~A}$ matriz julga prioridades de ação sobre os critérios competitivos, colocando as importâncias dos diferentes critérios e uma escala de desempenho comparado à concorrência juntas em uma matriz. Em termos simples, a escala de importância classifica critérios competitivos como "menos importantes", "qualificadores" e "ganhadores de pedidos"; o desempenho é julgado em comparação com o dos concorrentes em uma escala que vai de "muito pior que os concorrentes" até "muito melhor que os concorrentes". Por ela, a matriz define zonas que mostram se os critérios deveriam demandar ação de melhoria como prioridade ou não. 
A reunião começou com a definição de quais critérios eram minimamente relevantes para a empresa. Foi decidido que cinco critérios básicos - custo, qualidade, velocidade, confiabilidade e flexibilidade eram, em princípio, relevantes. Durante a reunião, os critérios foram discutidos um por um até que os participantes chegaram a um consenso. Não somente foi considerada a do GEM sentiram que ainda não estavam preparados para definir os objetivos e classificar ações prioritárias. "Confiabilidade, por exemplo, que é nossa prioridade número um, ainda não está objetivamente mensurada pela empresa. Como nós poderemos saber aonde chegar, se não sabemos nem mesmo onde estamos?", disse o gerente de manufatura durante uma das reuniões.

Figura 2 - Matriz de importância-desempenho

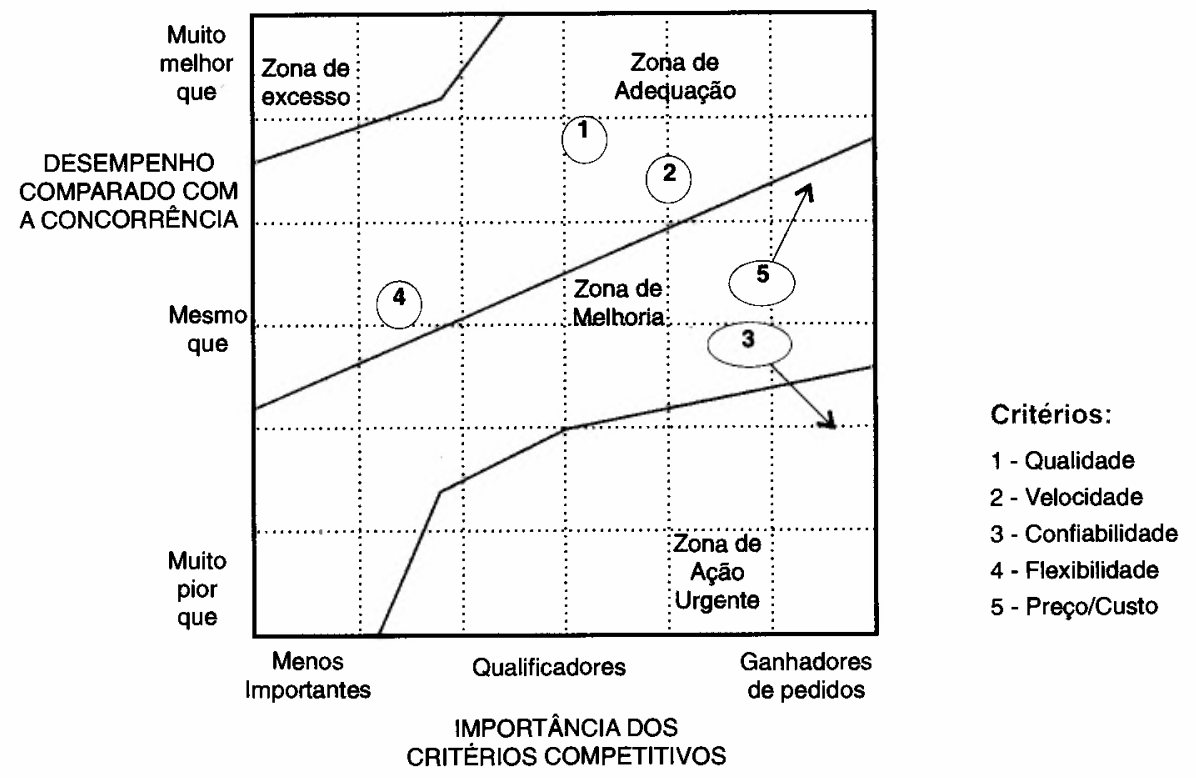

Nota: baseada em SLACK, N. The manufacturing advantage. London: Mercury Books, 1991.

situação atual, como também as tendências para o futuro. Importância e desempenho foram discutidos separadamente para cada uma das duas dimensões, uma escala de nove pontos $^{21}$ foi usada, a qual foi preenchida após se chegar a um consenso sobre cada critério. Após um processo algo doloroso para alcançar um consenso sobre todos critérios predeterminados, a matriz de importância e desempenho foi construída. Cada critério foi colocado na área correspondente, de acordo com a informação obtida dos gráficos de importância e desempenho. A matriz final de uma das famílias de produto é mostrada na Figura 2. As setas representam tendências futuras.

O próximo passo foi definir as ações prioritárias quanto aos objetivos e determinar como o processo deveria ser implementado no nível operacional. Contudo, os membros
O GEM resolveu então que, antes de continuar com o processo em nível operacional, era necessário estudar os critérios competitivos mais importantes de maneira mais profunda para avaliar o desempenho atual da empresa. Durante um mês, foram conduzidos estudos dos determinantes, dentro da empresa, de confiabilidade e custo (priorizados como 1 e 2, de acordo com a matriz de importância-desempenho - ver Figura 2). Ambos os estudos levantaram algumas questões muito importantes. $O$ estudo sobre confiabilidade mostrou que a empresa entregava mais de $30 \%$ de seus pedidos com atraso, conclusão essa que não tinha sido obtida apenas com o levantamento da percepção dos gerentes. Já o estudo sobre custos evidenciou oportunidades de trabalhar com custos mais eficientes (materiais importados), o que não havia sido considerado até então.
21. Idem, ibidem. 
O processo em nível operacional: quebrando as barreiras através de abordagem interna clientefornecedor

O estudo descrito na seção anterior tornou possível definir objetivos para os critérios competitivos mais importantes. $\mathrm{O}$ processo poderia então continuar no nível operacional. Devido às características do meio ambiente, o GEM decidiu adotar uma abordagem fornecedor-cliente interno: o processo seria firmemente baseado em negociações entre departamentos dentro da empresa. A suposição básica é que todos na organização têm clientes (que podem ser tanto funções internas como clientes externos) e deve servi-los da melhor maneira possível, dados os limites impostos pelas restrições de recursos e também tendo em mente os objetivos, políticas e estratégias da corporação. ${ }^{22} \mathrm{As}$ funções "cliente" e "fornecedora" devem negociar e chegar a um entendimento sobre o nível de serviços e mercadorias que o fornecedor deve oferecer. Eles devem concordar sobre um nível específico de desempenho dos critérios que melhor representam o "ponto de contato" entre as duas funções. A negociação pode basearse na análise das "lacunas" (gaps) entre o nível exigido de desempenho dos critérios pela função "cliente" e o nível de desempenho que é oferecido pela função "fornecedora".

O passo inicial foi construir uma rede explícita de clientes e fornecedores internos. Foi decidido que a estrutura organizacional da empresa seria mantida (dado que, por decisão da alta direção, uma completa reengenharia da empresa não deveria ser considerada). Duas ou três pessoas de cada departamento foram selecionadas para tornarem-se membros do GEM no nível operacional. Elas foram apresentadas aos principais conceitos de estratégia de manufatura através de uma série de seminários e debates com os membros senior do GEM. Após os conceitos estarem claros e homogêneos entre os participantes, os clientes e fornecedores internos começaram seu processo de negociação, objetivando determinar as prioridades e os partamentos. O processo ocorreu através de uma série de passos:

- Estabelecer os critérios locais: os representantes de cada par fornecedor-cliente foram colocados juntos para estabelecer quais critérios locais deveriam ser relevantes para a negociação. Eles inicialmente poderiam propor qualquer critério que considerassem importantes para seu departamento.

- Ligar os critérios locais com os globais: objetivando evitar "ótimos locais" em cada negociação cliente-fornecedor, o GEM construiu matrizes para relacionar cada critério local com os critérios competitivos globais. $O$ Quadro 1 mostra um exemplo de matriz desenvolvida para a negociação entre os departamentos de vendas e de planejamento da produção. A importância de cada critério local para cada negociação foi obtida dessa matriz; os critérios que estão fortemente relacionados com os critérios competitivos globais priorizados pela empresa foram considerados os mais importantes na negociação interna.

- Avaliar fornecedores internos e auto-avaliação: para ajudar na negociação entre os departamentos, dois tipos de folhas de trabalho foram desenvolvidas. Para cada critério de negociação duas folhas de trabalho eram preenchidas: uma pelo cliente, avaliando o fornecedor, e outra pelo fornecedor, para auto-avaliação. (Essas folhas de trabalho foram preenchidas em uma reunião com dois ou três membros do grupo GEM e representantes do departamento envolvido.) $O$ apêndice 1 mostra um exemplo de folha de trabalho a ser preenchida por clientes internos. A folha de trabalho de auto-avaliação para ser preenchida pelo fornecedor interno pedia o mesmo tipo de informação, objetivando a facilitação do processo de negociação. Além de dar uma idéia mais clara do desempenho desejado em cada critério, as folhas de trabalho trouxeram muitas sugestões de melhoria que puderam ser utilizadas mais tarde na fase de implementação.

- Negociação: de posse das informações das folhas de trabalho, os departamentos foram colocados juntos para comparar e 
discutir suas respostas ("como eu me avaliei" comparado com "como meu cliente me avaliou" - o objetivo era ajudar na função de negociação para ter padrões de afirmativas mais homogêneos) e construir uma matriz importância-desempenho. Foi decidido que as negociações deveriam se iniciar no departamento de vendas e ser então "puxadas para trás" pela rede de suprimentos interna, terminando no departamento de compras. Essa decisão visava garantir que a demanda do cliente externo pelo produto (qualidade, nível de inovação, taxas de introdução de novos produtos), entrega (tempo, confiabilidade) e serviço - sentidos pelo departamento de vendas - seriam disseminados por toda a organização. Ao encaminhar o processo de um lado da empresa para outro, passando por todos os departamentos, as necessidades e expectativas do cliente dirigem as negociações.

A matriz de importância-desempenho utilizada nessa fase foi adaptada da matriz

Quadro 1 - Matriz de correspondência para a negociação entre vendas e planejamento da produção

\begin{tabular}{|l||l|l|l|l|l|}
\hline $\begin{array}{l}\text { Critérios } \\
\text { Locais }\end{array}$ & Qualidade & Velocidade & Confiabilidade & Flexibilidade & Custo \\
\hline Exatidão & $\odot \odot$ & & $\odot$ & & $\odot$ \\
\hline Confiabilidade & & $\odot \odot \odot$ & $\odot \odot$ & $\odot$ \\
\hline Velocidade & & $\odot \odot \odot$ & $\odot$ & $\odot \odot \odot$ \\
\hline Custo & & & & & \\
\hline
\end{tabular}

Apêndice 1 - Exemplo de folha de trabalho para avaliação do fornecedor interno

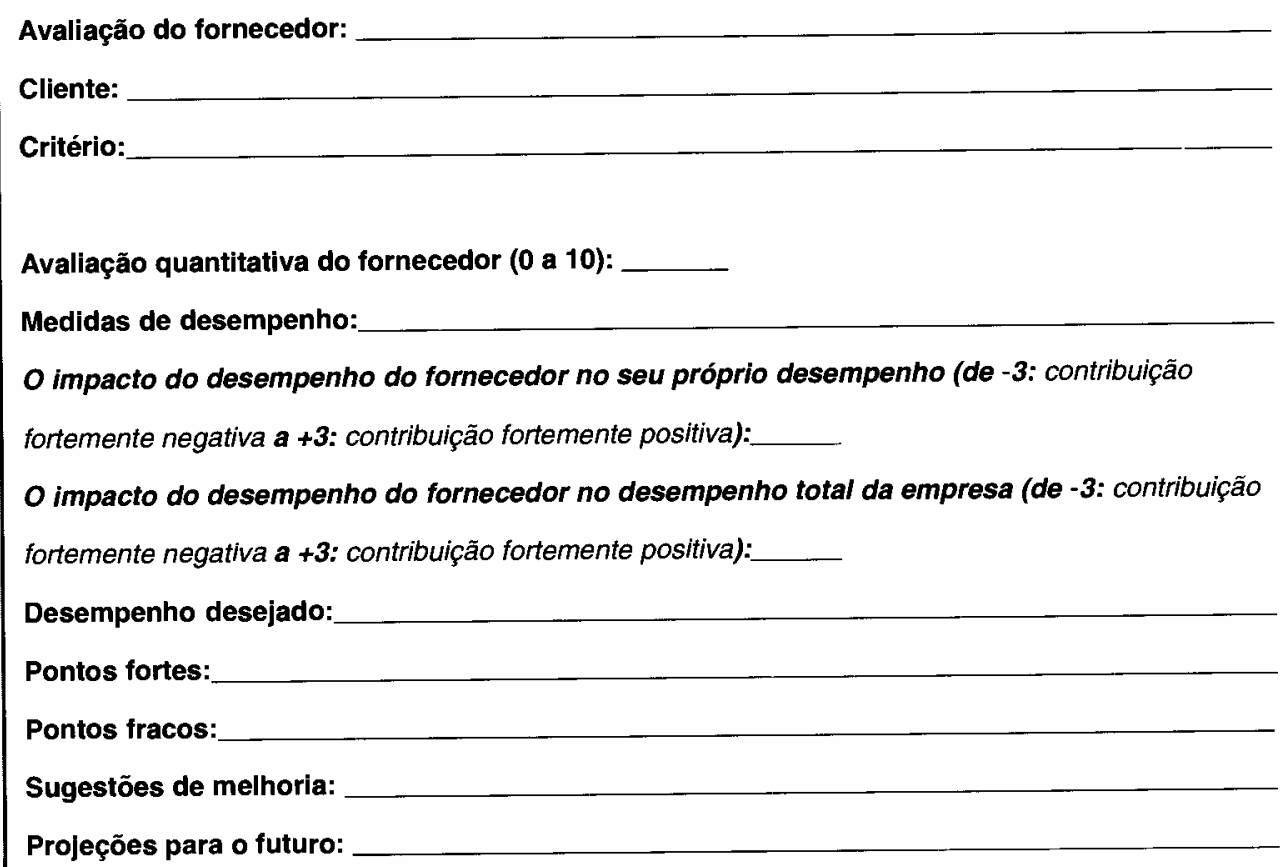


23. SLACK, N. Op. cit.

24. SLACK, N. The importance-performance matrix as a determinant of improvement priority. Intemational Journal of Operations and Production Management. v.14, n.5. p.59-75,1994.

25. PETTIGREW, A., WHIPP, R. Managing change for competitive success. Oxford: Blackwell, 1991 importância-desempenho de Slack $^{23}$ (ver Figura 2). A importância de cada critério foi estabelecida com base nos resultados da matriz mostrada no Quadro 1. Os critérios locais com a mais forte relação com os critérios competitivos priorizados por toda a empresa foram considerados os mais importantes.

Diferentemente da matriz de Slack, ${ }^{24} \mathrm{o}$ desempenho não foi comparado com o dos concorrentes, mas com as expectativas dos clientes internos. ${ }^{25}$ Com base nos resultados das folhas de trabalho, os critérios foram classificados em uma escala de "pior que o necessário" a "melhor que o necessário". Necessário, neste caso, significa o desempenho-padrão que o cliente necessita para cumprir seus objetivos estratégicos. A matriz mostrada na Figura 3 ajuda a determinar quais critérios locais requerem ações prioritárias de melhoria.

- Estabelecer planos de ação: baseados nos resultados da matriz, os departamentos tiveram então de negociar planos de ação para melhorar o desempenho nos critérios prioritários. Uma folha de trabalho foi desenvolvida para ajudar nessas deter- minações. Para cada critério prioritário, os departamentos deveriam determinar quais ações de melhoria deveriam ser providenciadas nas dez principais áreas de decisão: capacidade, instalações, tecnologia, integração vertical, recursos humanos, gerenciamento da qualidade, fluxo de materiais, desenvolvimento de novos produtos, medidas de desempenho e organização. Essas ações de melhorias foram então apresentadas à alta direção para aprovação. Forças-tarefas foram então estabelecidas, objetivando colocar os projetos em prática.

\section{Atingindo a proatividade usando cenários: o papel dos modelos contingenciais}

A primeira fase do projeto havia acabado. Um modelo inicial tinha sido desenvolvido, o que resultou em planos operacionais de ação. Ao desenvolver o processo, o objetivo de ajudar a derrubar as barreiras havia sido atingido, porém, era necessário mais. Não se queria simplesmente que as funções negociassem com o fornecedor interno tentando atender bem seu cliente interno. Nós os queríamos

Figura 3 - Matriz de importância-desempenho para a negociação interna cliente-fornecedor 
proativos. O conceito de "modelos contingenciais" foi, então, desenvolvido e incluído na estrutura. $\mathrm{Na}$ estrutura proposta, a proatividade é atingida através de considerações explícitas de futuros cenários possíveis de todas as funções.

Para desenvolver esses cenários, os representantes das funções e os analistas têm de estar conscientes dos desenvolvimentos atuais e prováveis em seus campos de interesse. No processo de negociação interna cliente-fornecedor, pessoas de outras funções eventualmente irão demandar deles alternativas, de maneira que possam estar mais bem preparados para atingir um melhor desempenho em suas próprias funções. Pessoas da manufatura, por exemplo, irão demandar do pessoal de finanças que estejam preparados para oferecer alternativas para se obter capital mais barato para investimentos. As pessoas de marketing irão exigir da manufatura alternativas tecnológicas para possíveis usos futuros que possam fornecer diferentes níveis de desempenhos competitivos relacionados à entrega, qualidade, custos e flexibilidade, de maneira que eles possam escolher de um grande leque de mercados aquele(s) a ser(em) visado(s) no futuro. Isso deveria motivar os representantes das diferentes funções a agir proativamente, na procura de novas alternativas em seus campos específicos.

Para as pessoas com funções particulares estarem habilitadas para imaginar cenários e também para que possam negociar com outras funções, elas devem desenvolver o que chamamos de "modelos contigenciais". Modelos contigenciais são definidos aqui como modelos conceituais formais que interligam possíveis contingências presentes e futuras (características, ações e decisões) com os vários "pontos de contato" entre as próprias funções e outras funções com as quais interagem. Em termos da interface marketing-manufatura, o pessoal de manufatura deve desenvolver modelos contigenciais que associem possíveis decisões e ações futuras (como investimento em equipamento, contratação e treinamento de pessoas, adoção de sistemas de controle, entre outras) com os critérios competitivos globais, qualificadores e ga- nhadores de pedidos. Isso requer que o pessoal da manufatura reconheça e monitore novos desenvolvimentos (metodológicos e tecnológicos) no processo de produção, de modo que eles estejam habilitados a avaliar possibilidades de atender ou não as exigências de marketing e também elaborar cenários alternativos para eles. O pessoal de marketing, por outro lado, deve desenvolver modelos contigenciais que lhes permitam associar critérios qualificadores e ganhadores de pedidos com diferentes segmentos de mercado, de maneira que possam reformular os planos de marketing (mercado-alvo, freqüência de introdução de novos produtos, entre outros) se mudanças ocorrerem no conjunto de critérios competitivos (ou no desempenho da manufatura nesses critérios) que a manufatura pode prover no presente ou no futuro. A Figura 5 ilustra o processo de negociação e o Apêndice 2 é um exemplo de folhas de trabalho para a operacionalização da proatividade das várias funções.

\section{O processo de replanejamento - disparado por eventos relevantes e tempo}

No modelo proposto, o replanejamento do processo pode ser disparado por eventos relevantes e tempo, diferentemente do disparo apenas pela passagem do tempo, como os principais métodos de desenvolvimento de estratégia de manufatura sugerem. Essa atitude prevenir a empresa de atrasos na resposta a mudanças relevantes que ocorrem entre os instantes em que devem ocorrer os replanejamentos. Esse processo de replanejamento pode ser disparado por qualquer função que considere que algo relevante tenha mudado ou tenha alta probabilidade de mudar, relativo a seu campo de interesse. Uma súbita e significativa mudança em taxas de importação é uma mudança típica e que pode disparar o processo de replanejamento de modo que toda a empresa junte seus esforços para enfrentar a nova situação trazida pela mudança. A folha de trabalho explicada na última seção (ver Apêndice 2) ajuda a formalizar o processo: a função que deseja disparar o processo de replanejamento 
preenche a folha de trabalho e a envia para outras funções; uma reunião é então agendada para decidir se há necessi- dade do processo de replanejamento ou apenas pequenos ajustes para a nova situação.

Figura 5 - Processo de negociação para a operacionalização da proatividade: exemplo da interface marketing-manufatura

\begin{tabular}{|c|c|c|c|c|}
\hline Nichos de & $\begin{array}{c}\text { Modelo } \\
\text { contingencial } \\
\text { (Marketing) }\end{array}$ & $\begin{array}{c}\text { Pontos de } \\
\text { contato } \\
\text { (Marketing/ } \\
\text { Manufatura) }\end{array}$ & $\begin{array}{c}\text { Modelo } \\
\text { contingencial } \\
\text { (Manufatura) }\end{array}$ & $\begin{array}{c}\text { de } \\
\text { gia }\end{array}$ \\
\hline Z & $\Omega$ & $\Omega$ & 几 & $\Omega$ \\
\hline $\begin{array}{l}\text { - produtos } \\
\text { - segmentos } \\
\text { - linha } \\
\text { - mix } \\
\text { - volume } \\
\text { - taxa de } \\
\text { mudança }\end{array}$ & $\begin{array}{l}\text { Relaciona nichos } \\
\text { de mercado a } \\
\text { pontos de } \\
\text { contato para a } \\
\text { negociação } \\
\text { marketing- } \\
\text { manufatura }\end{array}$ & $\begin{array}{l}\text { - custo } \\
\text { - qualidade } \\
\text { - tempo } \\
\text { - flexibilidade }\end{array}$ & $\begin{array}{l}\text { Relaciona } \\
\text { tecnologias a } \\
\text { pontos de } \\
\text { contato para a } \\
\text { negociação } \\
\text { marketing- } \\
\text { manufatura }\end{array}$ & $\begin{array}{l}\text { - tipos de } \\
\text { tecnologia } \\
\text { - inovações } \\
\text { tecnológicas } \\
\text { - custo e } \\
\text { tempo para } \\
\text { implementação }\end{array}$ \\
\hline
\end{tabular}

Apêndice 2 - Exemplo de folha de trabalho para construção de modelos contigenciais

Função:

Cenário A

Principais Características:

Custo \& Recursos necessários para a operacionalização:

Tempo para implementação:

Decisões futuras e ações:

Reflexão sobre os critérios:

Critério A ; Critério B ; Critério n-

\section{Cenário $X$}

Principais Características:

Custo \& Recursos necessários para a operacionalização:

Tempo para implementação:

Decisões futuras e ações:

Reflexão sobre os critérios:

Critério A ; Critério B ; Critério $n-$ 
Quadro 2 - Analisando o processo de acordo com o modelo de Pettigrew \& Whipp

\begin{tabular}{|l||l|}
\hline $\begin{array}{l}\text { Questões do processo } \\
\text { proposto relacionadas } \\
\text { aos fatores }\end{array}$ & Conclusões sobre os fatores \\
\hline
\end{tabular}

\section{AVALIAÇÃO DO MEIO AMBIENTE}

\begin{tabular}{|l||l|}
\hline - Entrevistas diretas com os & - Muito importante em ambientes turbulentos. \\
clientes, benchmarking. & - Mudanças constantes trazem diferentes visões da gerência \\
- Uso de cenários. & $\begin{array}{l}\text { sobre o meio ambiente. Essas diferenças devem ser cuidadosa- } \\
\text { mente debatidas antes de estabelecer ações, de outra maneira, } \\
\text { haverá problemas com o comprometimento dos gerentes em } \\
\text { relação ao projeto. }\end{array}$ \\
\hline
\end{tabular}

\section{LIDERANÇA DAS MUDANÇAS}

- Abordagem middledown-top-down.

- Uso do projeto-piloto para obter 0 comprometimento da gerência.
- A alta direção encarando muitos problemas relacionados a mudanças de meio ambiente encontra pouco tempo para estar atualizada com as novas técnicas desenvolvidas. Um conservadorismo resultante disso faz do desenvolvimento de novas idélas um fator difícil. Nesse caso, o uso de projetos-piloto disparados pela gerência média parece ser uma boa maneira de introduzir novas idéias e tecnologias.

\section{LIGAÇÃO DE MUDANÇAS ESTRATÉGICAS E OPERACIONAIS}

- Processo passo a passo.

- Abordagem interna cliente-fornecedor.
- Superar barreiras internas é essencial para quebrar estratégias em atividades operacionalizáveis.

- A abordagem cliente-consumidor interno é adequada para criar um clima favorável para o estabelecimento de metas.

\section{RECURSOS HUMANOS COMO ATIVO E PASSIVO}

\begin{tabular}{|l||l|}
\hline $\begin{array}{l}\text { - Negociação entre clientes } \\
\text { e fornecedores internos. } \\
\text {-Modelos contigenciais" }\end{array}$ & $\begin{array}{l}\text { - Para aumentar a consciência do pessoal, cada função deve estar } \\
\text { ativamente envolvida no processo. }\end{array}$ \\
$\begin{array}{l}\text { sendo construídos } \\
\text { através de toda a } \\
\text { organização para obter } \\
\text { proatividade. }\end{array}$ & \multicolumn{1}{|c|}{ COERÊNClA } \\
\hline $\begin{array}{l}\text { que garanta que o } \\
\text { desempenho dos } \\
\text { critérios locais suportem } \\
\text { os ganhadores de } \\
\text { pedidos globais. }\end{array}$ & $\begin{array}{l}\text { - Um "facilitador" do processo presente em todas as reuniōes é } \\
\text { essencial para se atingir a coerêncla desejada em todo o }\end{array}$ \\
\hline
\end{tabular}


Quadro 3 - Fases da pesquisa e conclusões

\begin{tabular}{|c|c|c|}
\hline Fases & $\begin{array}{l}\text { Ferramentas/métodos } \\
\text { utilizados }\end{array}$ & Conclusões \\
\hline $\begin{array}{l}\text { 1. Sentindo o } \\
\text { ambiente } \\
\text { inicial }\end{array}$ & Questionários & $\begin{array}{l}\text { - Ótimo para "preparar o terreno". } \\
\text { - Alguns mal-entendidos podem ocorrer } \\
\text { porque alguns conceitos não são ainda } \\
\text { conhecidos por todos. }\end{array}$ \\
\hline $\begin{array}{l}\text { 2. Formando um } \\
\text { consenso em } \\
\text { relação aos } \\
\text { conceitos de } \\
\text { estratégia } \\
\text { de manufatura }\end{array}$ & Palestras & $\begin{array}{l}\text { - Importante antes de se iniciar o processo. } \\
\text { - A mentalidade de "qualidade total" traz } \\
\text { resistência, os gerentes querem ser } \\
\text { excelentes em tudo e não concordam com a } \\
\text { idéla de priorizar critérios. Para evitar isso, } \\
\text { muitos exemplos reais devem ser utilizados } \\
\text { nas palestras. }\end{array}$ \\
\hline 3. Avaliação externa & $\begin{array}{l}\text { Entrevistas diretas } \\
\text { com clientes }\end{array}$ & $\begin{array}{l}\text { - Abordagem qualitativa traz informações } \\
\text { úteis dos clientes, inclusive informações } \\
\text { sobre concorrentes. } \\
\text { - As entrevistas devem ser conduzidas por } \\
\text { membros da manufatura e vendas juntos; o } \\
\text { relacionamento entre eles melhora durante o } \\
\text { processo. } \\
\text { - Os entrevistadores devem tentar não } \\
\text { responder/justificar as reclamações, mas } \\
\text { apenas ouvir os clientes; dessa maneira eles } \\
\text { tendem a dar mais informação. } \\
\text { - Em tais ambientes instáveis entrevistas } \\
\text { devem ser feitas regularmente e objetivar } \\
\text { antecipar/monitorar tendências do mercado. }\end{array}$ \\
\hline $\begin{array}{l}\text { 4. Contribuições } \\
\text { internas }\end{array}$ & Folhas de trabalho & $\begin{array}{l}\text { - A abordagem quantitativa faz a fase } \\
\text { seguinte (a matriz de importância- } \\
\text { desempenho) mais fácil. } \\
\text { - As respostas foram tão díspares em alguns } \\
\text { casos que uma reunião foi necessária para } \\
\text { debatê-las e chegar a um consenso; os } \\
\text { gerentes sentem que essas discussões são } \\
\text { muito importantes para o processo, } \\
\text { concordando que as diferenças são na } \\
\text { maioria próprias do ambiente incerto. }\end{array}$ \\
\hline $\begin{array}{l}\text { 5. Priorização de } \\
\text { critérios }\end{array}$ & $\begin{array}{l}\text { Matriz de } \\
\text { importância- } \\
\text { desempenho }\end{array}$ & $\begin{array}{l}\text { - É dificil chegar a um consenso e construir a } \\
\text { matriz; os gerentes sentem que um erro } \\
\text { nessa fase pode arruinar todo o processo. } \\
\text { Eles querem estar certos de todos os fatores } \\
\text { do debate. } \\
\text { - Representar tendências futuras na matriz é } \\
\text { muito importante em tais ambientes. }\end{array}$ \\
\hline
\end{tabular}




\begin{tabular}{|c|c|c|}
\hline $\begin{array}{l}\text { 6. Estudo dos } \\
\text { critérios } \\
\text { priorizados }\end{array}$ & $\begin{array}{l}\text { Sem ferramenta } \\
\text { especifica }\end{array}$ & $\begin{array}{l}\text { - Atingir um nivel de concordância na } \\
\text { priorização dos critérios não é sempre } \\
\text { suficiente; às vezes os gerentes precisam } \\
\text { debater antes de chegar a conclusões sobre } \\
\text { as prioridades, já que a mesma } \\
\text { característica ("flexibilidade”, por exemplo) } \\
\text { pode significar coisas diversas para } \\
\text { diferentes pessoas. }\end{array}$ \\
\hline $\begin{array}{l}\text { 7. Priorização de } \\
\text { critérios internos }\end{array}$ & $\begin{array}{l}\text { Matriz de } \\
\text { correspondência, } \\
\text { Matriz importância- } \\
\text { desempenho } \\
\text { (modificada) }\end{array}$ & $\begin{array}{l}\text { - O uso do mesmo tipo de matriz utilizado na } \\
\text { priorização dos critérios globais é muito } \\
\text { positiva; os envolvidos "falam a mesma } \\
\text { língua" ao longo de toda a organização. } \\
\text { - Uma ferramenta formal para relacionar critérios } \\
\text { locais com globais é essencial para evitar ótimos } \\
\text { locais (e. g., a matriz de correspondência). }\end{array}$ \\
\hline $\begin{array}{l}\text { 8. Negociação para } \\
\text { planos de ação }\end{array}$ & Folhas de trabalho & $\begin{array}{l}\text { - Em tais ambientes, negociações entre } \\
\text { todas as funções é muito eficaz em } \\
\text { responder rapidamente às mudanças. } \\
\text { - Um "facilitador" deve agir no processo de } \\
\text { negociação para garantir coerência. }\end{array}$ \\
\hline $\begin{array}{l}\text { 9. Atingindo a } \\
\text { proatividade }\end{array}$ & Folhas de trabalho & $\begin{array}{l}\text { - Conversar sobre construir cenários futuros é } \\
\text { muito dificil devido à cultura de "apagar } \\
\text { incêndios" existente nos ambientes turbulentos. }\end{array}$ \\
\hline
\end{tabular}

\section{Mudanças gerenciais: analisando o processo proposto de acordo com o modelo de Pettigrew e Whipp}

O desenvolvimento e implementação da estratégia de manufatura é uma mudança organizacional de grande porte. Pettigrew e Whipp sugerem cinco fatores centrais para lidar com mudanças organizacionais relevantes:

(1) avaliação do meio ambiente;

(2) liderando as mudanças;

(3) ligando mudanças estratégicas e operacionais;

(4) recursos humanos como "ativo" e como "passivo" da empresa;

(5) coerência.

O processo aqui descrito cobre essas cinco áreas, e algumas conclusões podem ser extraídas desses fatores (ver Quadro 2).

\section{CONCLUSÕES}

O modelo desenvolvido apresentado aqui está resumido no quadro 2 , com as conclusões sobre cada fase do processo.
Este artigo tenta contribuir para um tema muito pouco explorado na literatura: o desenvolvimento de estratégias de manufatura em ambientes que são conhecidos por sua incerteza e turbulência, tais como aqueles encontrados em países em desenvolvimento ou reorganizando suas economias. As conclusões são que as características de tais ambientes realmente clamam por soluções diferentes daqueles métodos normalmente encontrados na literatura. Aspectos como proatividade, superação de barreiras organizacionais e gerenciamento de mudanças ambientais exigem tratamentos diferentes porque eles são mais que necessários: são uma condição qualificadora para as empresas permanecerem no negócio (ver Quadro 3). No entanto, a generalização das proposições aqui contidas são discutíveis, já que elas são fortemente baseadas em uma aplicação principal em uma indústria específica, no meio ambiente e cultura brasileiros. Mesmo assim, espera-se que algumas das idéias desenvolvidas aqui possam ser úteis no debate deste tema tão importante.
* Os autores desejam agradecer à Sita. Pautla Reis Patrício pelo apoio na geração desta versāo do artigo. 